\title{
The effects of collagen peptides on muscle damage, inflammation and bone turnover following exercise: a randomized, controlled trial
}

\author{
Tom Clifford $^{1}$ (D) $\cdot$ Matthew Ventress ${ }^{2} \cdot$ Dean M. Allerton $^{2} \cdot$ Sarah Stansfield ${ }^{2} \cdot$ Jonathan C. Y. Tang $^{3,4}$. \\ William D. Fraser ${ }^{3,4} \cdot$ Barbara Vanhoecke $^{4}$. Janne Prawitt ${ }^{4} \cdot$ Emma Stevenson $^{1}$
}

Received: 18 October 2018 / Accepted: 19 January 2019 / Published online: 19 February 2019

(C) The Author(s) 2019

\begin{abstract}
This study examined whether consuming collagen peptides (CP) before and after strenuous exercise alters markers of muscle damage, inflammation and bone turnover. Using a double-blind, independent group's design, 24 recreationally active males consumed either $20 \mathrm{~g} \mathrm{day}^{-1}$ of $\mathrm{CP}$ or a placebo control (CON) for 7 days before and 2 days after performing 150 drop jumps. Maximal isometric voluntary contractions, countermovement jumps (CMJ), muscle soreness (200 $\mathrm{mm}$ visual analogue scale), pressure pain threshold, Brief Assessment of Mood Adapted (BAM+) and a range of blood markers associated with muscle damage, inflammation and bone turnover C-terminal telopeptide of type 1 collagen $(\beta-C T X)$ and $N$-terminal propeptides of type 1 pro-collagen (P1NP) were measured before supplementation (baseline; BL), pre, post, 1.5, 24 and $48 \mathrm{~h}$ post-exercise. Muscle soreness was not significantly different in $\mathrm{CP}$ and $\mathrm{CON}(P=0.071)$ but a large effect size was evident at $48 \mathrm{~h}$ postexercise, indicative of lower soreness in the CP group $(90.42 \pm 45.33 \mathrm{~mm}$ vs. CON $125.67 \pm 36.50 \mathrm{~mm}$; ES $=2.64)$. CMJ height recovered quicker with $\mathrm{CP}$ than $\mathrm{CON}$ at $48 \mathrm{~h}(P=0.050$; $\mathrm{CP} 89.96 \pm 12.85$ vs. CON $78.67 \pm 14.41 \%$ of baseline values; $\mathrm{ES}=0.55)$. There were no statistically significant effects for the other dependent variables $(P>0.05)$. $\beta$-CTX and P1NP were unaffected by $\mathrm{CP}$ supplementation $(P>0.05)$. In conclusion, $\mathrm{CP}$ had moderate benefits for the recovery of $\mathrm{CMJ}$ and muscle soreness but had no influence on inflammation and bone collagen synthesis.
\end{abstract}

Keywords Muscle soreness $\cdot$ Exercise recovery $\cdot$ Collagen $\cdot$ Hydrolyzed collagen $\cdot$ Bone turnover $\cdot$ Inflammation

Handling Editor: D. Bartolini.

Electronic supplementary material The online version of this article (https://doi.org/10.1007/s00726-019-02706-5) contains supplementary material, which is available to authorized users.

Tom Clifford

tom.clifford@newcastle.ac.uk

1 Institute of Cellular Medicine, Faculty of Medical Sciences, School of Biomedicine, Newcastle University, Newcastle upon Tyne NE2 4HH, UK

2 School of Biomedical Sciences, Newcastle University, Newcastle upon Tyne, UK

3 Norwich Medical School, University of East Anglia, Norfolk and Norwich University Hospital Norfolk, Norwich, UK

4 Rousselot BVBA, Ghent, Belgium

\section{Introduction}

Strenuous exercise involving repetitive lengthening muscle contractions can result in ultrastructural damage to the myofibrils and surrounding extracellular matrix (ECM) (Clarkson and Sayers 1999; Hyldahl and Hubal 2014). Outwardly, this damage manifests as swelling, pain, soreness, and a loss of function in the damaged limbs (Clarkson and Sayers 1999; Hyldahl and Hubal 2014). Indeed, power, strength and motor control can all be significantly affectedto what extent and for how long largely being dictated by the intensity of the exercise, genetic variability and/or training status of the individual (Clarkson and Sayers 1999; Paulsen et al. 2012; Hyldahl and Hubal 2014). Nonetheless, even mild induction of these symptoms can negatively affect performance in athletic populations. In more severe cases, tasks required for daily living, such as stair climbing and walking might also be affected (Dannecker and Koltyn 2014).

While most research into the aetiology of exerciseinduced muscle damage (EIMD) has focused on the 
myofibres, there is a growing appreciation for the important role of the ECM (Hyldahl and Hubal 2014; Mackey and Kjaer 2016). Structurally, the ECM of skeletal muscle consists of several different collagens, integrins, proteoglycans and glycoproteins, which together form a complex architectural network designed to transmit myofibrillar forces throughout the muscle fibre and provide structural integrity (Gillies and Lieber 2011; Hyldahl and Hubal 2014; Mackey and Kjaer 2016). Of these components, collagen is the most abundant and appears to be highly sensitive to mechanical loading (Gillies and Lieber 2011). Indeed, a number of animal and human studies have reported significant increases in muscle collagen turnover $<72 \mathrm{~h}$ following muscle-damaging exercise, indicative of extensive degradation and remodelling in the ECM (Han et al. 1999; Mackey et al. 2004; Miller et al. 2005). Direct damage to the ECM has also been observed histologically, in which the ECM is seen to be detached from the myofibre with immunochemical staining (Stauber et al. 1990). Indirect evidence of ECM damage also exists, with a number of studies showing that collagen-specific amino acids, most notably hydroxyproline, markedly increase in the circulation in the days following muscle-damaging exercise (Brown et al. 1999; Tofas et al. 2008). As suggested by Crameri et al. (2007), the consequence of such damage is likely to be a sub-optimal distribution of myofibrillar forces throughout the muscle fibre, which, in turn, reduces muscle contractile function. This assertion is supported by a recent animal study that found that mice with a genetic mutation encoding for collagen type $\mathrm{V} 1$, which is important in the formation of the basement membrane of the ECM, generate significantly less muscle force than their healthy counterparts (Zou et al. 2014). This raises the possibility that attenuating damage to the ECM and/or attempting to accelerate the remodelling process might be of benefit for recovery of muscle function after strenuous physical exercise.

While most interventions attempting to accelerate ECM remodelling are pharmacological (Mackey and Kjaer 2016), there is a growing interest in the effects of supplements containing collagen-specific peptides, or gelatin (partially hydrolyzed collagen), on collagen synthesis (Shaw et al. 2016). These supplements are derived from the connective tissue of animals and contain high amounts of the collagenspecific amino acids (AA) hydroxyproline, glycine and proline that together comprise almost two-thirds of the total $\mathrm{AA}$ in collagen ( $\mathrm{Li}$ and $\mathrm{Wu} 2018$ ). Upon ingestion, these amino acids are markedly elevated in the blood, demonstrating high absorption rates and availability to cells for biological functions (Ohara et al. 2007; Shaw et al. 2016). A recent in vitro study demonstrated that incubating engineered ligaments with serum from individuals consuming $15 \mathrm{~g}$ of gelatin stimulated collagen synthesis (Shaw et al. 2016). Although in vivo studies are still scarce, Shaw et al.
(2016) also showed that ingestion of 5 or $15 \mathrm{mg}$ of gelatin augmented bone collagen synthesis following acute mechanical loading (jump rope), as evidenced by increase in the bone formation marker pro-collagen type 1 amino-terminal propeptide (P1NP). This led the authors to speculate that these collagen-specific peptides could serve as a useful supplement to aid connective tissue repair after exercise and/ or injury.

If these AA can stimulate collagen synthesis, it would be reasonable to assume that increasing their availability after exercise might be able to modify ECM dysfunctioneither by attenuating damage or enhancing the remodelling process - and that this might, in turn, accelerate acute functional recovery following strenuous exercise. In support, there is now a growing body of evidence to suggest collagen hydrolysate supplementation could attenuate some of the symptoms associated with EIMD—especially muscle soreness. Indeed, several studies have indicated that collagen peptide (CP) ingestion relieves muscle and joint pain in diseases such as osteoarthritis (Kumar et al. 2015; Flechsenhar and McAlindon 2016; Woo et al. 2017). Some recent studies also indicated reductions in self-reported joint pain in physically active but otherwise healthy individuals (Clark et al. 2008; Zdzieblik et al. 2017). One study has also reported that $\mathrm{CP}$ attenuated creatine kinase (CK) activity following muscle-damaging exercise, indicative of enhanced muscle recovery (Lopez et al. 2015). Collectively, the aforementioned findings suggest that $\mathrm{CP}$ hold promise as a recovery aid following strenuous exercise and that they warrant further exploration.

Consequently, the aim of this study was to examine whether consuming $\mathrm{CP}$ before and after a bout of strenuous exercise could attenuate indirect markers of muscle damage and recovery. Our primary outcome measures were functional in nature; muscle soreness and muscle function, given they are widely accepted to be the most valid and reliable markers of EIMD and recovery (Warren et al. 1999) and have the most practical relevance to active populations. Secondary outcomes included systemic markers of muscle damage, inflammation, muscle soreness and bone collagen turnover. The latter was analyzed to try to get an idea of how the $\mathrm{CP}$ affect post-exercise collagen turnover in vivo.

\section{Methods}

\section{Participants}

Twenty-four males, who were recreationally active (defined as exercising $\sim 2$ day week ${ }^{-1}$ ) but unaccustomed to highforce plyometric exercise, volunteered for this study (see Table 1 for physical characteristics). Prior to study entry, participants completed a medical screening questionnaire 
Table 1 Participant's physical characteristics, baseline scores for each variable, and macronutrient content of their dietary intake throughout the study (average of 3 days) in each group; collagen peptides (CP) and placebo control $(\mathrm{CON})$

\begin{tabular}{lcc}
\hline Variable & \multicolumn{2}{l}{ Group } \\
\cline { 2 - 3 } & CP & CON \\
\hline Age (years) & $24.1 \pm 4.3$ & $24.8 \pm 4.8$ \\
Mass $(\mathrm{kg})$ & $79.6 \pm 7.5$ & $76.1 \pm 10.9$ \\
Height $(\mathrm{cm})$ & $177.8 \pm 3.8$ & $180.2 \pm 6.7$ \\
MIVC $(\mathrm{N})$ & $638.3 \pm 81.1$ & $588.3 \pm 114.7$ \\
CMJ $(\mathrm{cm})$ & $32.4 \pm 7.9$ & $32.6 \pm 6.4$ \\
PPT $(\mathrm{N})$ & $67.9 \pm 20.4$ & $72.6 \pm 21.14$ \\
BAM $+(\mathrm{AU})$ & $5.3 \pm 1.8$ & $5.2 \pm 1.9$ \\
VAS $(\mathrm{mm})$ & $12.2 \pm 10.2$ & $15.4 \pm 13.3$ \\
Energy intake & $25.52 \pm 9.09$ & $26.07 \pm 4.75$ \\
$\quad\left(\mathrm{kcal} \mathrm{kg} \mathrm{bm}{ }^{-1}\right)$ & & $3.34 \pm 0.72$ \\
Cho $\left(\mathrm{g} \mathrm{kg} \mathrm{bm}^{-1}\right)$ & $2.97 \pm 1.03$ & $1.18 \pm 0.27$ \\
Pro $\left(\mathrm{g} \mathrm{kg} \mathrm{bm}^{-1}\right)$ & $1.26 \pm 0.46$ & $0.97 \pm 0.30$ \\
Fat $\left(\mathrm{g} \mathrm{kg} \mathrm{bm}^{-1}\right)$ & $0.99 \pm 0.43$ & \\
\hline
\end{tabular}

Values are mean $\pm \mathrm{SD} ; n=12$ per group

Cho carbohydrate, Pro protein, MIVC maximal isometric voluntary contraction, $C M J$ countermovement jump height, $P P T$ pressure pain threshold, VAS visual analogue scale for muscle soreness

and were excluded if they had a known food allergy, currently, or had recently used anti-inflammatory medications (within 1 month of participation), had a previous history of cardiovascular disease or any other contraindication to the study procedures. They were prohibited from using any reputed recovery interventions during the trial (e.g., compression garments, whey protein shakes, and ice baths). The study received institutional ethical approval (ethics number 1412_1/15934/2017) and all volunteers provided written informed consent for their participation.

\section{Experimental design}

In a double-blind, placebo-controlled, independent group design, participants were randomized to one of the two experimental groups; a treatment group, which received $20 \mathrm{~g} \mathrm{day}^{-1}$ of $\mathrm{CP}$, and a control group, which received an isoenergetic and isovolumic placebo CON. Baseline (BL) measures were collected at least 7 days prior to the main exercise trial and consisted of subjective wellbeing, muscle soreness, a venous blood sample, pressure pain threshold (PPT), countermovement jump height (CMJ) and maximal isometric voluntary contractions (MIVC). The baseline CMJ scores were used to randomly match the participants in each group. Following this visit, participants consumed their assigned supplements ( $\mathrm{CP}$ or $\mathrm{CON}$ ) for 7 days before muscle-damaging exercise. Supplements were consumed twice per day; one serving (10 g) in the morning with breakfast, and another with their evening meal. On the 8th day, before and after repeating the baseline measures outlined above, they performed 150 drop jumps to induce muscle damage. On this day, participants consumed one serving of $\mathrm{CP}$ or CON 40 min before beginning the pre-exercise measures, and another immediately after the post-exercise measures, alongside a snack (two slices of toasted bread with $10 \mathrm{~g}$ of butter; $246 \mathrm{kcal}, 32.8 \mathrm{~g}$ carbohydrate, $5.6 \mathrm{~g}$ protein and $10.3 \mathrm{~g}$ fat; Clifford et al. 2016a). Sixty minutes after finishing their supplement and snack, a final blood sample was taken. $24 \mathrm{~h}$ later, participants repeated the baseline measures outlined above, consuming one supplement $40 \mathrm{~min}$ prior, and one with their evening meal. This was repeated $48 \mathrm{~h}$ post-exercise, with the exception of the evening supplement.

\section{Muscle-damaging exercise protocol}

Muscle damage was induced with a drop jump protocol adapted from a previous study (Clifford et al. 2016a). In the present study, participants performed a total of 150 drop jumps from a $60 \mathrm{~cm}$ box. The jumps were performed in sets of $6 \times 25$ (separated by a 2 min rest period) and each jump separated by $10 \mathrm{~s}$. For each jump, participants were instructed to land on $2 \mathrm{ft}$, squat to a $\sim 90^{\circ}$ knee angle, and then jump vertically with maximal effort.

\section{Dietary control}

Before attending the laboratory for their baseline visit, participants provided a $24 \mathrm{~h}$ recall of their current dietary intake. This was visually inspected by a sports dietician for macronutrient composition and, alongside baseline CMJ scores, was used as a blocking factor for randomizing participants into each group. This was to ensure that the habitual dietary intake of the participants in each group was relatively homogenous. The participants were also instructed to record their dietary intake on the day before muscle-damaging exercise, the day of the exercise, and the day following ( 3 days in total). This was to check for differences in the macronutrient composition of the participant's diet during the exercise part of the trial.

\section{Countermovement jump height}

Countermovement jump (CMJ) was used as an indirect measure of muscle power. As in a previous study (Clifford et al. 2016a), jumps were performed with an OptoJump system (Optojump, Italy) and required participants to descend into a squat (to $\mathrm{a} \sim 90^{\circ}$ knee angle) before jumping vertically with maximum effort. Hands remained on the hips throughout the movement. The best of three efforts (separated by a 60 s rest period) was used for analysis. The inter-day coefficient of variation (CV) for this test was calculated as $3.0 \%$. 


\section{Maximal isometric voluntary contraction}

MIVC were measured with a portable strain gauge (MIE Medical Research Ltd., Leeds, UK) according to the methods outlined previously (Clifford et al. 2016a). Briefly, participants had a perspex gauze strapped to their ankle and while sitting in an upright position were instructed to maximally extended their right knee flexor for a $3 \mathrm{~s}$ contraction. The peak value $(\mathrm{N})$ from three maximal contractions (separated by a $60 \mathrm{~s}$ rest period) was used for analysis. The inter-day CV for this measure was calculated as $3.9 \%$.

\section{Muscle soreness}

Muscle soreness was measured as both subjective pain and pressure pain threshold (PPT), as per previously described methods (Clifford et al. 2016a, b). For subjective pain, after performing a squat (at $\sim 90^{\circ}$ knee flexion), participants rated their level of muscle soreness (lower limbs only) by drawing a vertical line on a horizontal visual analogue scale (VAS), in which 0 represented 'no soreness' and $200 \mathrm{~mm}$ represented 'unbearably painful'. The line placement was measured with a ruler and recorded.

PPT was measured with a handheld digital algometer (Wagner Instruments, Greenwich CT, US). A cylindrical flat-headed probe was applied to three pre-marked sites on the muscle belly: rectus femoris, mid-way between the anterior patella and inguinal fold; vastus lateralis, mid-way between the superior aspect of the greater trochanter and head of the tibia; and gastrocnemius, most medial aspect of the calf at relaxed maximum girth. When the participant indicated the pressure applied at each site was causing pain, the score on the algometer was recorded in $\mathrm{N} \mathrm{cm}^{-2}$ as their PPT. The measure was repeated one more time and for a third time if the second and first recordings deviated by more than $10 \mathrm{~N} \mathrm{~cm}^{-2}$. To improve inter-day reliability, participant measures were taken by the same individual. The CV for this measure was calculated as $9.5 \%$.

\section{Supplements}

The CP supplement was provided by Rousselot BVBA (Ghent, Belgium) and is commercially available as Peptan ${ }^{\circledR}$. Each serving contained $10 \mathrm{~g}$ of hydrolyzed collagen peptides derived from bovine hide. Each serving of the CON contained $10 \mathrm{~g}$ of pure maltodextrin with no AA; this was also supplied by Rousselot BVBA. Both supplements were packaged as powder in identical $10 \mathrm{~g}$ sachets. As in a previous study (Shaw et al. 2016), they were consumed with water and $50 \mathrm{ml}$ of Ribena Light (Suntory, China), which is rich in vitamin $\mathrm{C}$ ( $80 \mathrm{mg}$ per serving) and, therefore, thought to enhance collagen synthesis.

Due to the paucity of studies on CP and EIMD, selecting the most appropriate dose and protocol was a challenge. The rationale for our eventual selection was based on evidence from several lines of enquiry: those examining nutritional supplements on EIMD; those examining collagen pharmacokinetics; and those examining collagen synthesis. Foremost is the timings. We opted to provide the supplements twice daily for 7 days before exercise because studies with fruit juices and branched chain AA showed that such a protocol, typically known as a pre-load, was beneficial for symptoms of EIMD (Sousa et al. 2013). Although previous studies assessing $\mathrm{CP}$ on joint pain tend to provide more chronic doses ( $\geq 8$ weeks), we felt this would compromise compliance and limit the applicability of our findings, given our aim was to pilot test the acute benefits of this supplement for more athletic populations. Second, on the day of exercise (and 24 and $48 \mathrm{~h}$ post-exercise), the supplements were consumed $40 \mathrm{~min}$ prior to the recovery measures being taken. This rationale was based on recent findings (Shaw et al. 2016), which found that blood levels of proline, glycine, hydroxylysine and hydroxyproline peaked 30-60 min following $15 \mathrm{~g}$ of gelatin ingestion. They also found that collagen synthesis was augmented after exercise with this dosage protocol. We, therefore, reasoned that taking the outcome measures when these specific AA peaked in the blood would give us the best chance of detecting a benefit - if one existed.

\section{Subjective mood questionnaire}

At each time point, participants completed a questionnaire for qualitatively assessing individuals' mood, recovery status and overall performance readiness (Shearer et al. 2017). The questionnaire contains six items from The Brief Assessment of Mood (BAM) and four questions relating to confidence, motivation, muscle soreness and sleep quality. As a result, the questionnaire has been named The Brief Assessment of Mood Adapted (BAM+). For each of the ten questions, participants drew a line on a $100 \mathrm{~mm}$ VAS, anchored with "not at all" and "extremely" at each end. The lines were measured and an overall score calculated by summing the values for the positively associated questions $(\times 4)$ and subtracting them from the sum of the negatively associated questions $(\times 6)$.

\section{Blood sampling}

All the blood samples were venous and collected via venipuncture. At all six time points (pre-baseline, pre-exercise, post-exercise, $1.5 \mathrm{~h}$ post-exercise, $24 \mathrm{~h}$ and $48 \mathrm{~h}$ post-exercise), blood was drawn into a $10-\mathrm{ml}$ vacutainer for serum 
and a 10- and 4-ml vacutainer coated with di-potassium ethylene diamine tetra-acetic acid (EDTA). Samples were centrifuged at $2500 \mathrm{rpm}\left(4{ }^{\circ} \mathrm{C}\right)$ for $10 \mathrm{~min}$ to separate the supernatant, which was stored in aliquots at $-80^{\circ}$ and only thawed for analysis in the morning of the analysis. The 4-ml EDTA vacutainer was transported to a local hospital for haematological analysis.

An automated haematology system (Sysmex XE-2100, Illinois, US) was used to measure white blood cell, neutrophil and lymphocyte counts before and after exercise. Creatine kinase (CK), aspartate transaminase (AST), alanine transaminase (ALT) and lactate dehydrogenase (LDH) were measured in serum using an automated system based on an electro-chemiluminescence method (Roche Modular, Roche Diagnostics, UK). According to data provided by the analyzing laboratory (Newcastle Laboratories, UK), the CV's for the haematological analysis and the markers measured by electro-chemiluminescence were $<10 \%$ and $<5 \%$, respectively. Interleukin-6 (IL-6) was measured in serum using a commercially available ELISA kit (R\&D Systems, Oxford, UK). Plasma beta-nerve growth factor ( $\beta$-NGF) was measured using an ELISA according to the manufacturer's instructions (Thermo Fisher Scientific, MA, US); results were read at $450 \mathrm{~nm}$ absorbance. The CV's for IL-6 and $\beta$-NGF were 9 and $12 \%$, respectively.

\section{Bone turnover markers}

As in a previous study (Townsend et al. 2017), $\beta$-isomerized C-terminal telopeptide ( $\beta$-CTX) and P1NP were measured by electro-chemiluminescence on an automated system (Roche Diagnostics, Mannheim, Germany). Intra and interassay CVs for this analysis were $<5 \%$.

\section{Data analysis}

All data are expressed as mean $\pm \mathrm{SD}$; an $\alpha$ level of $\leq 0.05$ was considered statistically significant. MIVC, CMJ, muscle soreness, PPT, BAM + and all blood variables were analyzed using a mixed model analysis of variance ANOVA with two treatment levels (group) (CP vs. $\mathrm{CON}$ ) and five or six repeated measures time points (time) (BL, pre, post, $1.5 \mathrm{~h}, 24 \mathrm{~h}$, and $48 \mathrm{~h}$ ). $\beta$-NGF data were not normally distributed (according to $\alpha \leq 0.05$ on the Kolmogorov-Smirnov test) and were, therefore, $\log$ transformed prior to analysis. If the ANOVA indicated a significant time effect (a change in values from $B L$ at other time points pre- and post-exercise, in both groups), a group $\times$ time interaction effect (a difference between $\mathrm{CP}$ and $\mathrm{CON}$ at any time point: BL, pre, post, $1.5 \mathrm{~h}, 24 \mathrm{~h}$, and $48 \mathrm{~h}$ ) or a group effect (difference in $\mathrm{CP}$ and CON across all time points), then least significant difference post hoc analysis was performed to locate where the differences lie. In the event of a significant violation of sphericity, Greenhouse-Geisser adjustments were used.

Instead of relying solely on $P$ values to determine the effects of the treatment, as is now discouraged-especially with lower sample sizes (Halsey et al. 2015), the data were also analyzed using magnitude-based inferences (MBI), which encompasses measures of effect size (ES) and confidence intervals, enabling us to get an idea of how meaningful any observed changes were. In addition, as this was a proof of principle study, that is, it is the first study to assess the effects of the intervention on these specific outcomes, we felt this statistical approach would allow us to better detect subtle differences that can be missed when solely relying on null hypothesis significance testing (NHST) (due to low sample size, high inter-individual variability) but are, nonetheless, still clinically useful or worthy of further exploration (Halsey et al. 2015; Page 2014).

For MBI analysis, data were analyzed with a published spreadsheet that calculates the magnitude of change of the intervention based on the between group mean effects and $\pm 90 \%$ confidence intervals (CI) (Batterham and Hopkins 2006). This analysis allows probabilistic inferences to be made not only about the potential benefits of the intervention on the dependent variables, but also the size of these effects (Hopkins 2002; Batterham and Hopkins 2006). The probabilistic thresholds for an effect were as follows: $<1 \%$ almost certainly none, $1-5 \%$ very unlikely, $5-25 \%$ unlikely, 25-75\% possibly, 75-95\% likely, 95-99\% very likely, and $>99 \%$ almost certainly. The effects were deemed unclear if the $\pm 90 \%$ CI crossed the positive and negative boundaries of the smallest worthwhile change, which was set a priori as 0.2 or $1 / 5$ of the between subject's standard deviation. Effect size (ES) magnitudes were calculated as the difference in means/SD for both groups and interpreted as trivial 0.0-0.2, small $0.2-0.6$, moderate $0.6-1.2$, large $1.2-2.0$, very large 2.0-4.0, and extremely large 4.0. As recommended (Hopkins 2002), blood variables were analyzed as factors, to account for the large percentage changes, while continuous variables (CMJ, MIVC, and PPT) were log transformed and then analyzed as percentage changes from baseline. To avoid scaling errors associated with Likert scales, both muscle soreness and the BAM + were not log transformed and instead analyzed from the raw values. All the values are compared to the baseline values collected before any supplementation.

\section{Results}

Participant's physical characteristics, baseline scores for each variable, and average macronutrient intake throughout the testing period are presented in Table 1 . There were no group difference in any of these variables $(P>0.05)$; with MBI analysis, effects were all unclear. For all the 
dependent variables, time effects using MBI analysis (mean effects, $\pm 90 \%$ CI, with qualitative inferences) are presented in Tables S1 and S2 (Supplementary Material). There were notable changes in the $\mathrm{CP}$ vs. CON group at various time points post-exercise; the mean changes, along with the $90 \%$ CI for these variables are displayed in Tables 2, 3, 4 .

\section{Muscle soreness and pressure pain threshold}

A time effect for increased muscle soreness was observed $(P=0.001)$ (Fig. 1). There was no group $\times$ time interaction $(P=0.202)$ but muscle soreness did tend to be lower in the CP group (group effect; $P=0.071$ ). Table 2 displays mean changes, along with the $90 \%$ CI for muscle soreness and PPT with MBI analysis; CP was possibly beneficial for reducing soreness at $24 \mathrm{~h}$ post-exercise (CP $106.67 \pm 43.98 \mathrm{~mm}$ vs. CON $139 \pm 35.68 \mathrm{~mm})$ and likely beneficial at $48 \mathrm{~h}$ post-exercise (CP $90.42 \pm 45.33 \mathrm{~mm}$ vs. CON $125.67 \pm 36.50 \mathrm{~mm})$. The ES at $24 \mathrm{~h}$ and $48 \mathrm{~h}$ post for CP were 2.40 and 2.64 , respectively, suggesting a very large effect was present. Exercise decreased PPT (time effect $P=0.001)$ but no group $\times$ time interactions of group effects were present $(P>0.05)$. For MBI analysis, all effects were trivial or unclear with PPT, and ES were small $(<0.50)$.

Table 2 Group effects of $\mathrm{CP}$ on functional and subjective performance markers (muscle soreness, CMJ, MIVC, PPT and BAM +)

\begin{tabular}{|c|c|c|c|}
\hline Variable & Time point & $\begin{array}{l}\text { Mean effect }{ }^{\mathrm{a}}, \pm 90 \% \\
\mathrm{CI}^{\mathrm{b}}\end{array}$ & Qualitative inference \\
\hline \multirow[t]{3}{*}{ Soreness } & BL-POST & $14.7, \pm 36.2$ & Unclear \\
\hline & $\mathrm{BL}-24 \mathrm{~h}$ & $29.1, \pm 25.3$ & Possible decrease \\
\hline & $\mathrm{BL}-48 \mathrm{~h}$ & $32.0, \pm 25.5$ & Likely decrease \\
\hline \multirow[t]{3}{*}{ CMJ } & BL-POST & $-1.3, \pm 7.4$ & Trivial \\
\hline & BL-24 h & $-9.1, \pm 11.1$ & Possible increase \\
\hline & $\mathrm{BL}-48 \mathrm{~h}$ & $15.2, \pm 16.1$ & Likely increase \\
\hline \multirow[t]{3}{*}{ MIVC } & BL-POST & $-4.2, \pm 6.7$ & Unclear \\
\hline & BL-24 h & $9.5, \pm 13.6$ & Likely increase \\
\hline & $\mathrm{BL}-48 \mathrm{~h}$ & $9.1, \pm 13.9$ & Unclear \\
\hline \multirow[t]{3}{*}{ PPT } & BL-POST & $11.5, \pm 17.2$ & Unclear \\
\hline & BL-24 h & $7.9, \pm 18.5$ & Unclear \\
\hline & $\mathrm{BL}-48 \mathrm{~h}$ & $-0.4, \pm 16.3$ & Trivial \\
\hline \multirow[t]{3}{*}{$\mathrm{BAM}+$} & BL-POST & $0.4, \pm 1.7$ & Trivial \\
\hline & $\mathrm{BL}-24 \mathrm{~h}$ & $0.5, \pm 1.2$ & Trivial \\
\hline & $\mathrm{BL}-48 \mathrm{~h}$ & $0.4, \pm 1.3$ & Trivial \\
\hline
\end{tabular}

$C O N$ control, $C P$ collagen peptides, $M I V C$ maximal isometric voluntary contraction, $C M J$ countermovement jump height, $P P T$ pressure pain threshold, $B A M+$ Brief Assessment of Mood Adapted

${ }^{\mathrm{a}}$ Mean effect of CP-CON

${ }^{\mathrm{b}} \pm 90 \% \mathrm{CI}$ : add and subtract this number to the mean effect to obtain the $90 \%$ CI's for the true difference

${ }^{c}$ Qualitative inference is the likelihood that the true value will have the observed magnitude
Table 3 Group effects of $\mathrm{CP}$ on serum proteins

\begin{tabular}{llll}
\hline Variable & Time point & $\begin{array}{l}\text { Mean effect }^{\mathrm{a}}, \\
\pm 90 \% \mathrm{CI}^{\mathrm{b}}\end{array}$ & Qualitative inference \\
\hline ALT & BL-PRE & $0.85, \pm 1.17$ & Likely decrease \\
& BL-POST & $0.81, \pm 1.16$ & Likely decrease \\
& BL-1.5 h & $0.80, \pm 1.17$ & Likely decrease \\
& BL-24 h & $0.73, \pm 1.26$ & Likely decrease \\
& BL-48 h & $0.69, \pm 1.29$ & Very likely decrease \\
AST & BL-PRE & $1.05, \pm 1.26$ & Unclear \\
& BL-POST & $0.99, \pm 1.33$ & Unclear \\
& BL-1.5 h & $0.87, \pm 1.21$ & Likely decrease \\
& BL-24 h & $0.76, \pm 1.46$ & Likely decrease \\
& BL-48 h & $0.81, \pm 1.43$ & Unclear \\
LDH & BL-PRE & $1.00, \pm 1.10$ & Unclear \\
& BL-POST & $0.95, \pm 1.13$ & Unclear \\
& BL-1.5 h & $1.05, \pm 1.21$ & Possible increase \\
& BL-24 h & $0.94, \pm 1.13$ & Unclear \\
& BL-48 h & $0.93, \pm 1.14$ & Unclear \\
CK & BL-PRE & $0.98, \pm 1.27$ & Unclear \\
& BL-POST & $1.08, \pm 1.47$ & Unclear \\
& BL-1.5 h & $0.72, \pm 1.16$ & Very likely decrease \\
& BL-24 h & $0.77, \pm 1.64$ & Unclear \\
& BL-48 h & $0.90, \pm 1.69$ & Unclear \\
& & &
\end{tabular}

$C K$ creatine kinase, $L D H$ lactate dehydrogenase, AST aspartate transaminase, $A L T$ alanine transaminase

${ }^{\mathrm{a}}$ Mean effect of $\mathrm{CP}-\mathrm{CON}$

${ }^{\mathrm{b}} \pm 90 \% \mathrm{CI}$ : add and subtract this number to the mean effect to obtain the $90 \%$ CI's for the true difference

${ }^{\mathrm{c}}$ Qualitative inference is the likelihood that the true value will have the observed magnitude

\section{Counter movement jump height and maximal isometric voluntary contraction}

$\mathrm{CMJ}$ and MIVC values are presented in Fig. 1. CMJ height was reduced in both groups after exercise (time effect; $P=0.001)$ but recovery was faster with $\mathrm{CP}$ (group $\times$ time effect; $P=0.040)$ at $48 \mathrm{~h}$ post-exercise $(P=0.050)$. MBI analysis suggested that $\mathrm{CP}$ was also possibly beneficial for the recovery of CMJ height at $24 \mathrm{~h}$ post-exercise $(\mathrm{CP}$ $86.65 \% \pm 11.94$ vs. CON $79.69 \pm 12.64 \%$ of baseline values; $\mathrm{ES}=0.33)$ and likely beneficial at $48 \mathrm{~h}$ post $(\mathrm{CP}$ $89.96 \pm 12.85$ vs. CON $78.67 \pm 14.41 \%$ of baseline values; $\mathrm{ES}=0.55$; Table 2). MIVC was reduced in both groups post-exercise (time effect; $P=0.001$ ) but no group $\times$ time or group effects were present $(P>0.05)$. At $24 \mathrm{~h}$ postexercise, MIVC was $85.35 \pm 15.77 \%$ of baseline values in $\mathrm{CP}$ and $78.44 \pm 17.7 \%$ in CON, indicating a likely benefit of CP with MBI analysis (Table 2); however, the ES was small (0.51). 
Table 4 Group effects of collagen peptides (CP) and control (CON) on biochemical parameters

\begin{tabular}{|c|c|c|c|}
\hline Variable & Time point & $\begin{array}{l}\text { Mean effect } \\
\pm 90 \% \mathrm{CI}^{\mathrm{a}}\end{array}$ & Qualitative inference \\
\hline \multirow[t]{5}{*}{ Leukocytes } & BL-PRE & $1.02, \pm 1.13$ & Possible increase \\
\hline & BL-POST & $1.08, \pm 1.15$ & Possible increase \\
\hline & $\mathrm{BL}-1.5 \mathrm{~h}$ & $1.11, \pm 1.15$ & Likely increase \\
\hline & $\mathrm{BL}-24 \mathrm{~h}$ & $1.08, \pm 1.11$ & Possible increase \\
\hline & $\mathrm{BL}-48 \mathrm{~h}$ & $1.04, \pm 1.19$ & Possible increase \\
\hline \multirow[t]{5}{*}{ Neutrophils } & BL-PRE & $1.15, \pm 1.24$ & Possible increase \\
\hline & BL-POST & $1.24, \pm 1.26$ & Possible increase \\
\hline & $\mathrm{BL}-1.5 \mathrm{~h}$ & $1.25, \pm 1.18$ & Likely increase \\
\hline & BL-24 h & $1.26, \pm 1.11$ & Likely increase \\
\hline & $\mathrm{BL}-48 \mathrm{~h}$ & $1.14, \pm 1.35$ & Possible increase \\
\hline \multirow[t]{5}{*}{ Monocytes } & BL-PRE & $0.72, \pm 1.39$ & Possible decrease \\
\hline & BL-POST & $0.90, \pm 1.2$ & Unclear \\
\hline & $\mathrm{BL}-1.5 \mathrm{~h}$ & $0.91, \pm 1.16$ & Unclear \\
\hline & BL-24 h & $0.84, \pm 1.24$ & Possible decrease \\
\hline & BL-48 h & $0.94, \pm 1.19$ & Unclear \\
\hline \multirow[t]{5}{*}{ Lymphocytes } & BL-PRE & $1.00, \pm 1.3$ & Trivial \\
\hline & BL-POST & $0.95, \pm 1.26$ & Unclear \\
\hline & BL-1.5 h & $1.08, \pm 1.20$ & Unclear \\
\hline & BL-24 h & $1.05, \pm 1.36$ & Unclear \\
\hline & $\mathrm{BL}-48 \mathrm{~h}$ & $0.97, \pm 1.17$ & Unclear \\
\hline \multirow[t]{5}{*}{$\beta$-CTX } & BL-PRE & $0.95, \pm 1.14$ & Unclear \\
\hline & BL-POST & $0.99, \pm 1.13$ & Trivial \\
\hline & $\mathrm{BL}-1.5 \mathrm{~h}$ & $1.04, \pm 1.16$ & Trivial \\
\hline & $\mathrm{BL}-24 \mathrm{~h}$ & $1.04, \pm 1.20$ & Possible increase \\
\hline & $\mathrm{BL}-48 \mathrm{~h}$ & $0.99, \pm 1.13$ & Trivial \\
\hline \multirow[t]{5}{*}{ P1NP } & BL-PRE & $1.02, \pm 1.10$ & Trivial \\
\hline & BL-POST & $1.03, \pm 1.12$ & Trivial \\
\hline & $\mathrm{BL}-1.5 \mathrm{~h}$ & $1.07, \pm 1.14$ & Possible increase \\
\hline & BL-24 h & $0.98, \pm 1.11$ & Trivial \\
\hline & $\mathrm{BL}-48 \mathrm{~h}$ & $1.00, \pm 1.12$ & Trivial \\
\hline \multirow[t]{5}{*}{ IL-6 } & BL-PRE & $0.81, \pm 2.84$ & Unclear \\
\hline & BL-POST & $0.48 \pm 2.35$ & Likely decrease \\
\hline & BL-1.5 h & $0.30, \pm 4.34$ & Likely decrease \\
\hline & $\mathrm{BL}-24 \mathrm{~h}$ & $0.61, \pm 2.69$ & Unclear \\
\hline & $\mathrm{BL}-48 \mathrm{~h}$ & $0.94, \pm 2.75$ & Unclear \\
\hline \multirow[t]{5}{*}{$\beta$-NGF } & BL-PRE & $1.03, \pm 1.20$ & Trivial \\
\hline & BL-POST & $0.90 \pm 1.33$ & Unclear \\
\hline & $\mathrm{BL}-1.5 \mathrm{~h}$ & $0.88, \pm 1.22$ & Unclear \\
\hline & BL-24 h & $0.91, \pm 1.42$ & Unclear \\
\hline & BL-48 h & $0.98, \pm 1.42$ & Unclear \\
\hline
\end{tabular}

$\beta$-CTX C-terminal telopeptide of type 1 collagen, $N$-terminal propeptides of type 1 pro-collagen P1NP, $I L-6$ interleukin- $6, \beta-N G F$ betanerve growth factor

${ }^{\mathrm{a}}$ Mean effect of CP-CON

${ }^{\mathrm{b}} \pm 90 \% \mathrm{CI}$ : add and subtract this number to the mean effect to obtain the $90 \%$ CI's for the true difference

${ }^{c}$ Qualitative inference is the likelihood that the true value will have the observed magnitude

\section{Brief Assessment of Mood Adapted}

$\mathrm{BAM}+$ scores were reduced in both $\mathrm{CP}$ and $\mathrm{CON}$ (time effect; $P=0.001$ ) but no time $\times$ group or group interactions were observed $(P>0.05$; Fig. 1$)$. With MBI analysis, effects were unclear or trivial at all time points and ES were small $(\leq 0.24)$; Table 2 displays mean changes, along with the $90 \%$ $\mathrm{CI}$ for $\mathrm{BAM}+$.

\section{Haematology}

Table 4 displays the group mean changes and $90 \%$ CI for all haemetatological variables. Leukocytes were increased from pre-supplementation to $1.5 \mathrm{~h}$ post in both groups (time effect; $P=0.0001$ ) but no group $\times$ time or group interaction were found ( $P>0.05 ;$ Fig. 2). However, MBI suggested leukocytes were possibly increased in $\mathrm{CP}$ at $1.5 \mathrm{~h}(\mathrm{CP} 1.1 \times / \div$ 1.2 vs. $\mathrm{CON} 1.0 \pm 1.2 ; \mathrm{ES}=0.37$ ) and possibly increased in the $\mathrm{CP}$ group at $24 \mathrm{~h}$ and $48 \mathrm{~h}$ post-exercise $(\mathrm{ES}=0.27$ and 0.12 , respectively). Similarly, neutrophils were increased from pre-supplementation to $1.5 \mathrm{~h}$ post-exercise in both groups (time effect; $P=0.001$ ) but no group $\times$ time or group interaction were found $(P>0.05)$. With MBI, a likely increase in the $\mathrm{CP}$ group was observed post-exercise $(\mathrm{ES}=0.52)$, at $1.5 \mathrm{~h}(\mathrm{CP} 1.4 \times / \div 1.4$ vs. $\mathrm{CON} 1.2 \times / \div 1.3$; $\mathrm{ES}=0.53)$ and $24 \mathrm{~h}(\mathrm{CP} 1.2 \times / \div 1.5$ vs. CON $0.9 \times / \div 1.3$; $\mathrm{ES}=0.54)$. A possible increase was also observed at $48 \mathrm{~h}$ post-exercise $(\mathrm{ES}=0.20)$. Monocytes were elevated immediately post-exercise only (time effect; $P=0.001$ ), with no group $\times$ time or group differences observed $(P>0.05)$. MBI suggested a likely decrease in monocytes in the $\mathrm{CP}$ group at pre- $(0.8 \times / \div 1.8$ vs. $\mathrm{CON} 1.1 \times / \div 1.1 ; \mathrm{ES}=0.91)$ and $24 \mathrm{~h}$ post-exercise $(\mathrm{CP} 0.81 \times / \div 1.3$ vs. $1.0 \times / \div 1.22 ; \mathrm{ES}=0.51)$. Lymphocytes were lower than BL at pre-exercise, $1.5 \mathrm{~h}, 24$ and $48 \mathrm{~h}$ post-exercise in both groups (time effect: $P=0.005$ ) but no group $\times$ interaction or group effects were observed $(P>0.05)$. All effects were either trivial or unclear with MBI analysis, and ES were small.

\section{Serum proteins, IL-6 and B-NGF}

Serum proteins, IL- 6 and $\beta$-NGF results are displayed in Fig. 3, and Tables 3 and 4 . ALT was elevated up to $1.5 \mathrm{~h}$ post-exercise (time effect; $P=0.014$ ) and a group $\times$ time interaction effect was present $(P=0.018)$. Post hoc analysis revealed that ALT levels were only different at BL between the groups $(P=0.023)$. Subsequent analysis when values were corrected for percentage change from baseline revealed no significant group differences (data not shown; $P>0.05$ ). However, with MBI analysis, ALT was likely decreased in the $\mathrm{CP}$ group at all time points from pre-exercise to $24 \mathrm{~h}$ post-exercise ( $\mathrm{ES}=0.35,0.46,0.67$ and 0.47 , respectively) and very likely decreased at $48 \mathrm{~h}$ post-exercise 

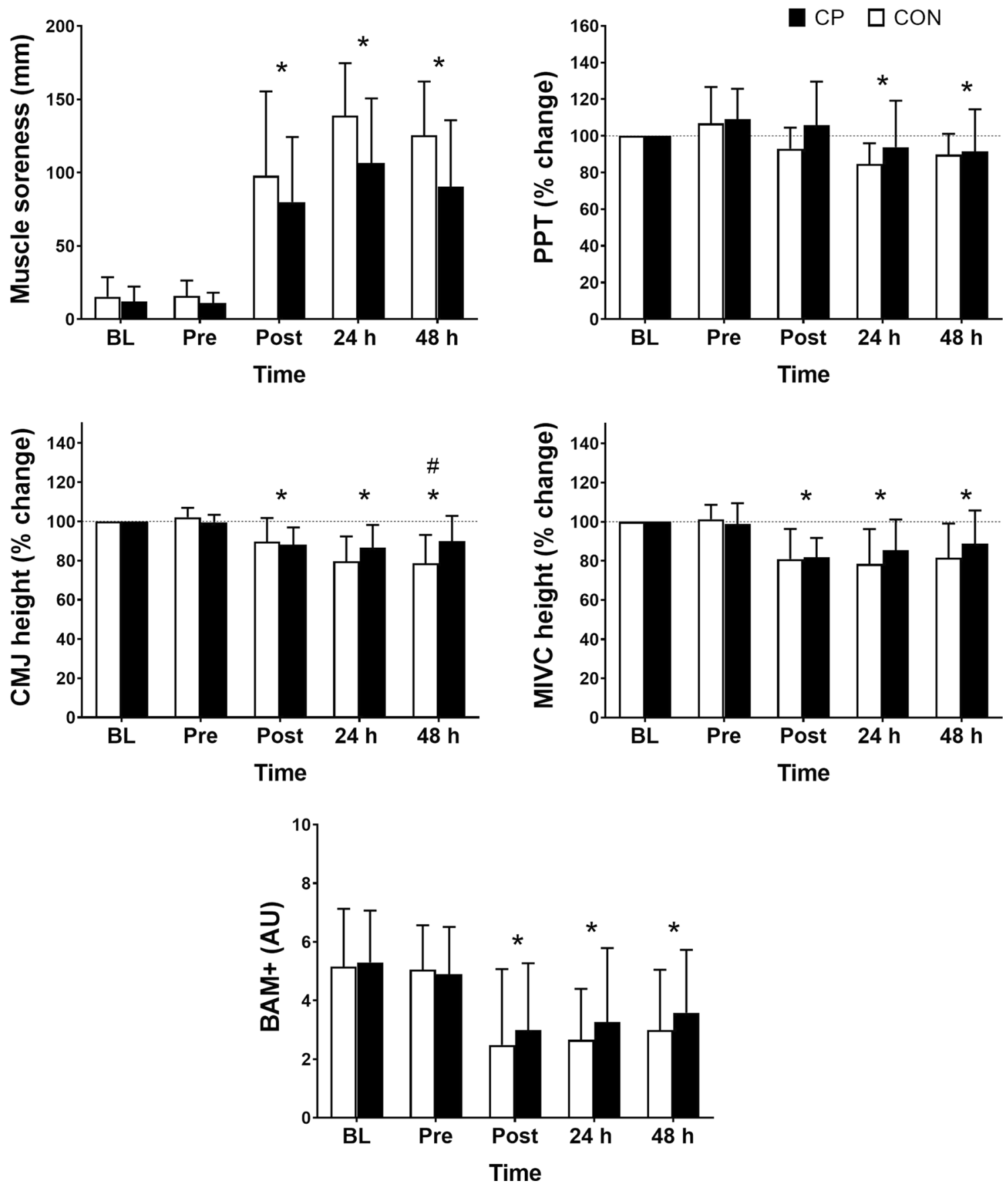

Fig. 1 Muscle soreness, pressure pain threshold (PPT), countermovement jump (CMJ) height, maximal isometric voluntary contraction (MIVC) and Brief Assessment of Mood Adapted (BAM+) at baseline (BL), pre-exercise (Pre), post-exercise (Post), $24 \mathrm{~h}$ and $48 \mathrm{~h}$ post-

$(\mathrm{ES}=0.79$; Table 3$)$. AST increased after exercise (time effect; $P=0.025)$ but no interaction or group effects were observed $(P>0.05)$. MBI analysis suggested AST was likely decreased at 1.5 and $24 \mathrm{~h}$ post-exercise $(\mathrm{ES}=0.43$ and 0.85; Table 3); however, effects were unclear at all other time points. $\mathrm{LDH}$ remained elevated at $48 \mathrm{~h}$ post-exercise exercise after collagen peptides (CP) or control (CON). PPT, CMJ and MIVC data presented as $\%$ of baseline values shown in Table 1. *Denotes time effect, $P<0.05$. "Denotes group $\times$ time interaction effect, $P<0.05$

(time effect; $P=0.001$ ) but no group $\times$ time interaction or group effects were observed $(P>0.05)$. With MBI, a possible increase in $\mathrm{LDH}$ levels were observed at $1.5 \mathrm{~h}$ post in $\mathrm{CP}$ but the ES was small (0.30) (Table 3). CK levels were still increased at $48 \mathrm{~h}$ post-exercise (time effect; $P=0.018$ ) but no group or interaction effect were observed. MBI analysis 

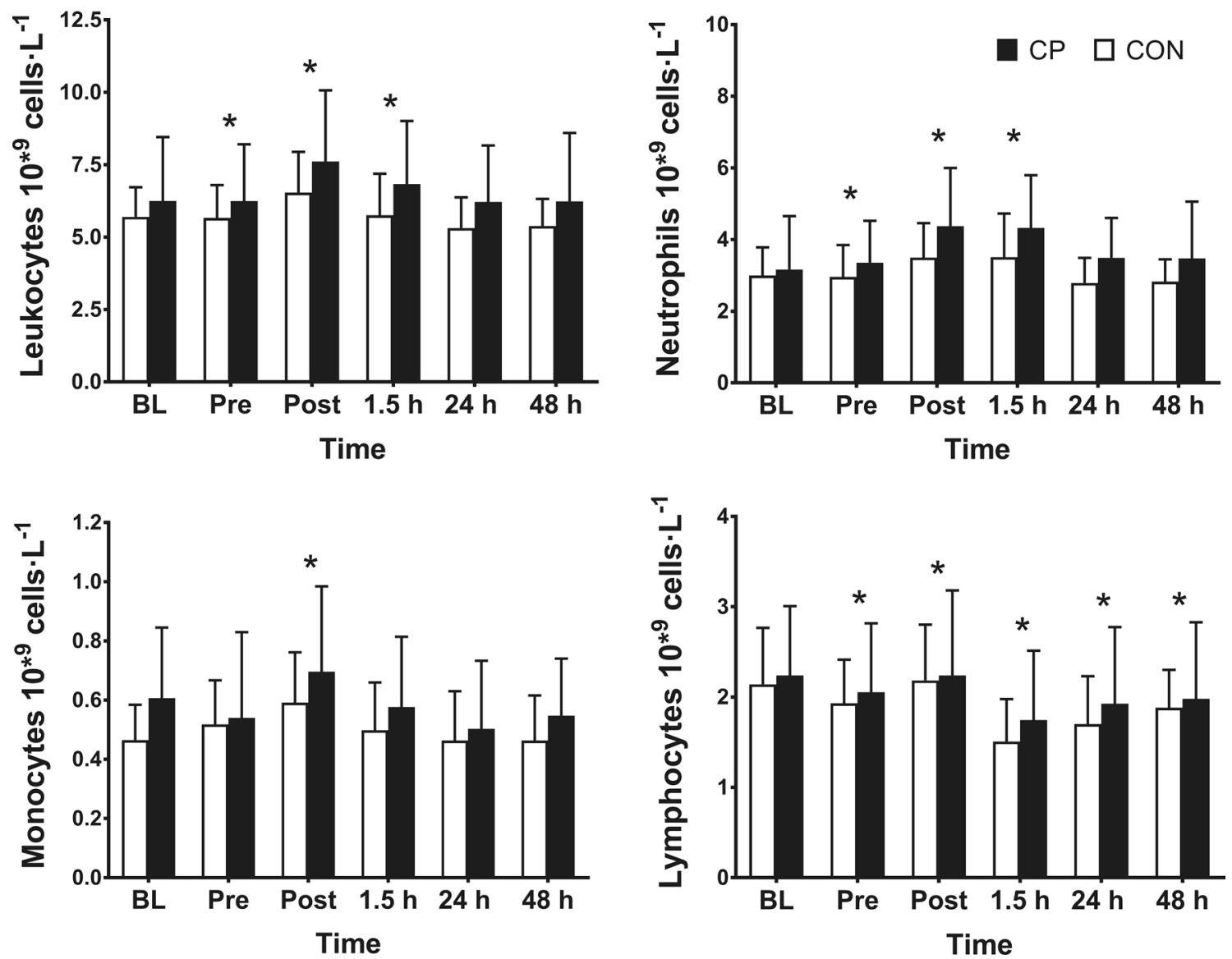

Fig. 2 Leukocytes, neutrophils, monocytes and lymphocytes at baseline (BL), pre-exercise (Pre), post-exercise (Post), $1.5 \mathrm{~h}, 24 \mathrm{~h}$ and $48 \mathrm{~h}$ postexercise after collagen peptides $(\mathrm{CP})$ or control $(\mathrm{CON})$. *Denotes time effect, $P<0.05$

suggested a very likely decrease in CK in CP $(54.1 \times / \div 93.9$ vs. $\mathrm{CON} 114.7 \times / \div 86.5 ; \mathrm{ES}=0.66$; Table 3$)$. There were no time, group or interaction effects for IL-6 $(P>0.05)$; however, MBI suggested a likely decrease with $\mathrm{CP}$ at postexercise and $1.5 \mathrm{~h}$ post-exercise ( $\mathrm{ES}=0.54$ and 0.91 , respectively; Table 4). For $\beta$-NGF, there were no time $(P=0.383)$, group $(P=0.481)$ or interaction effects $(P=0.880$; Fig. 3$)$. With MBI analysis, effects were deemed trivial or unclear at all time points (Table 4); ES were $\leq 0.20$ at all time points.

\section{Bone turnover}

Table 4 displays the group mean changes and $90 \%$ CI for bone turnover variables. P1NP was higher at post-exercise (time effect; $P=0.006$ ) but no group $\times$ interaction or group differences were present ( $P>0.05$; Fig. 4). MBI revealed a possible increase in $\mathrm{P} 1 \mathrm{NP}$ in $\mathrm{CP}$ vs. $\mathrm{CON}$ at $1.5 \mathrm{~h}$ postexercise $(1.0 \pm 1.1$ vs. $0.95 \pm 1.2 ; \mathrm{ES}=0.16)$. Compared to $\mathrm{BL}, \beta$-CTX was lower pre-exercise, post-exercise and $1.5 \mathrm{~h}$ post-exercise $(P<0.05)$ but no group $\times$ time or group effects were observed. A possible increase was observed in CP vs.
$\mathrm{CON}$ with $\mathrm{MBI}$ at $24 \mathrm{~h}$ post-exercise $(0.9 \pm 1.2$ vs. $0.8 \pm 1.4$; $\mathrm{ES}=0.09$ ).

\section{Discussion}

The main finding of this study is that CP supplementation accelerated the recovery of $\mathrm{CMJ}$ performance and tended to reduce muscle soreness following a bout of muscle-damaging exercise. The CP supplement had little to no influence on serum protein release, $\beta$-NGF, IL- 6 , and bone turnover markers post-exercise, but there were possibly some small increases in leukocyte numbers with CP supplementation post-exercise. This is the first study to suggest that $\mathrm{CP}$ could modulate the recovery process following eccentrically biased exercise.

Although not statistically significant, $(P=0.071)$, the large effect sizes suggest that those in the $\mathrm{CP}$ group reported less muscle soreness at 24 and $48 \mathrm{~h}$ post-exercise. Based on the $90 \% \mathrm{CI}$, the true impact of CP on muscle soreness was a 4.1-54.4 mm reduction on the VAS scale, which is arguably a meaningful decrease in athletic populations. This reduction 

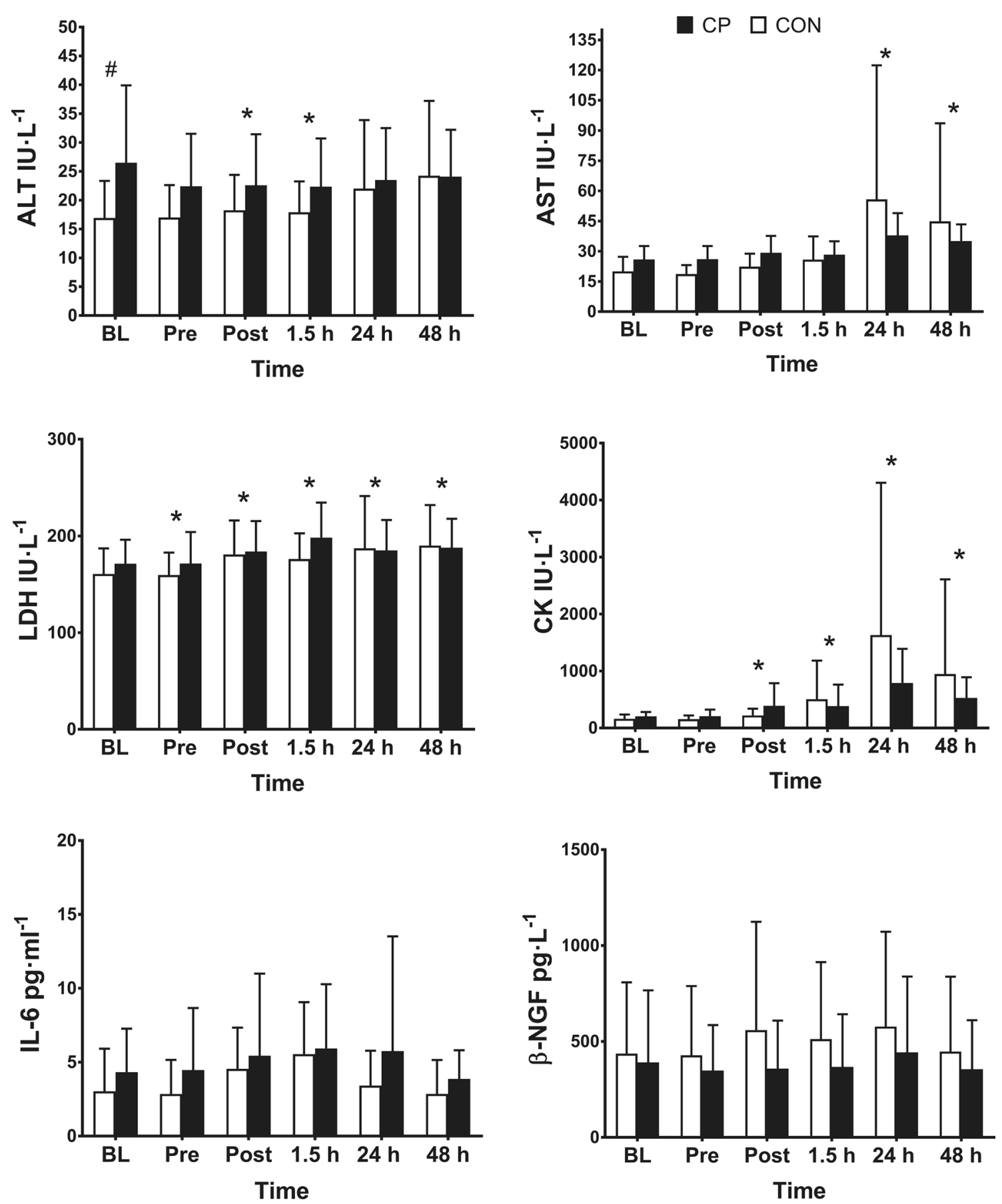

Fig. 3 Aspartate transaminase (ALT), alanine transaminase (AST), lactate dehydrogenase (LDH), creatine kinase (CK), interleukin-6 (IL-6) at baseline (BL), pre-exercise (Pre), post-exercise (Post), $1.5 \mathrm{~h}$,

$24 \mathrm{~h}$ and $48 \mathrm{~h}$ post-exercise after collagen peptides (CP) or control $(\mathrm{CON})$. *Denotes time effect, $P<0.05$. "Denotes group $\times$ time interaction effect, $P<0.05$

in soreness, however, was only evident from the subjective assessment with the VAS, as no group differences were detected in PPT. We are unsure of the precise reason for this discrepancy, but we are not the first to observe discrepant findings between soreness measured by a VAS and PPT (Lau et al. 2013)—including in response to an intervention

(cherry juice; Connolly et al. 2006). The lack of correlation between VAS and PPT found by Lau et al. (2013) led the authors to suggest that they likely measure different aspects of muscle soreness after exercise, concluding that a VAS provides a more accurate representation of muscle soreness than PPT. This could be in part because VAS eliminates 


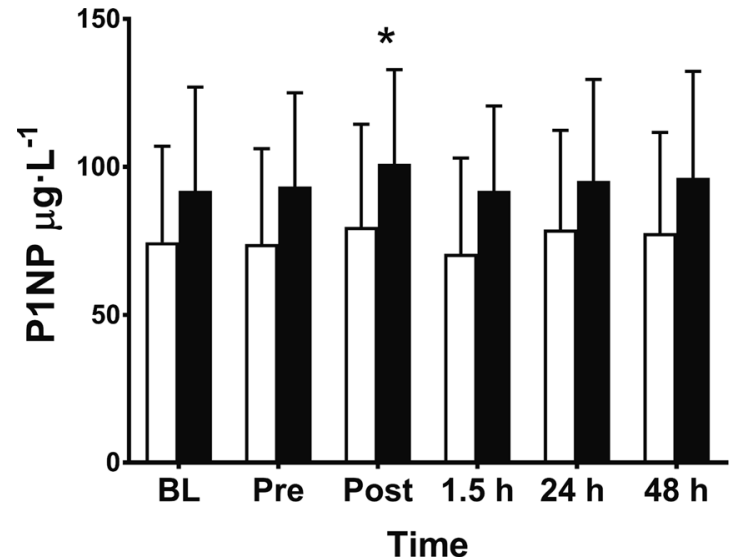

Fig. $4 \mathrm{~N}$-terminal pro-peptides of type 1 pro-collagen (P1NP) and C-terminal telopeptide of type 1 collagen $(\beta$-CTX) markers at baseline (BL), pre-exercise (Pre), post-exercise (Post), $1.5 \mathrm{~h}, 24 \mathrm{~h}$ and

any measurement issues from the person applying the PPT measure. It might also be of more practical significance, at least when measured actively (while performing a squat) like in the present study, compared to passively, like PPT is (while lying). Irrespective of the precise reason, these findings are consistent with several other studies measuring the effects of $\mathrm{CP}$ on subjective muscle soreness. Indeed, CP has consistently been shown to reduce muscle and joint pain in osteoarthritic patients and those with actively related joint pain (Kumar et al. 2015; Woo et al. 2017; Clark et al. 2008; Zdzieblik et al. 2017). Nonetheless, a similarly designed study did not report a pain reduction with CP after EIMD, but perhaps this was due to the small dose $(3 \mathrm{~g})$ provided in that study (Lopez et al. 2015).

The mechanisms by which $\mathrm{CP}$ might reduce muscle soreness are still not clear. The studies from the clinical and animal literature suggest a reduction in inflammation (Mizumura and Taguchi 2016; Dar et al. 2017) and, thus, we anticipated that $\mathrm{CP}$ ingestion might reduce inflammation, which, in the absence of biopsies, were measured in the blood. We also measured levels of the neurotrophic factor, $\beta$-NGF, as this has been strongly associated with exercise-induced muscle soreness (Mizumura and Taguchi 2016). Nonetheless, we found little evidence of an anti-inflammatory effect of CP, apart from a moderate decrease in IL-6 $1.5 \mathrm{~h}$ post-exercise $(\mathrm{ES}=0.91)$. Likewise, $\beta$-NGF factor was not attenuated in the $\mathrm{CP}$ group and, therefore, cannot explain the findings of the present study. The levels of $\beta$-NGF were actually not elevated above baseline levels post-exercise suggesting that circulatory levels are not associated with muscle soreness in healthy young males. Interestingly, there was actually some suggestion that neutrophil activity increased in the $\mathrm{CP}$ group; however, because the ES were small, they are probably not of any clinical relevance. Of course, we cannot rule out a local reduction in inflammation or any of the neurotrophic

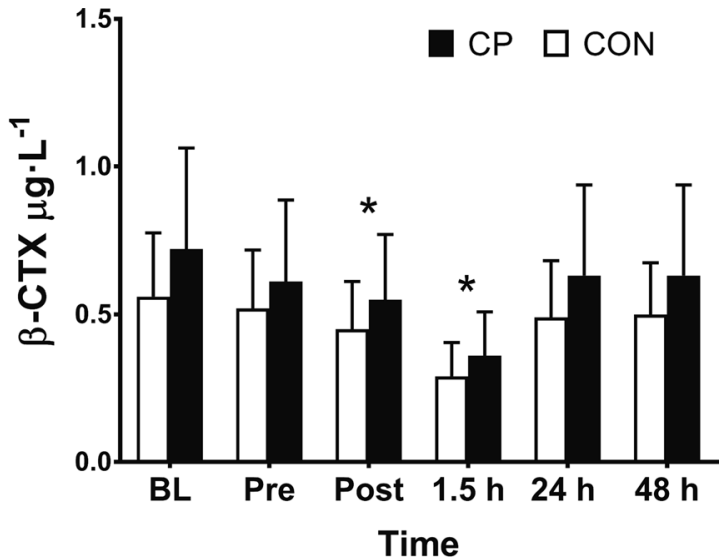

$48 \mathrm{~h}$ post-exercise after collagen peptides $(\mathrm{CP})$ or control $(\mathrm{CON})$. *Denotes time effect, $P<0.05$

factors with CP. Future attempts to elucidate the mechanisms by which CP might attenuate exercise-induced muscle soreness should include muscle biopsy samples.

It is also possible that the reduction in muscle soreness simply reflects a generally faster remodelling of the affected tissues with CP. Although there is little evidence to support such effects with CP at present, it was recently shown that hyperaminoacidemia, subsequent to whey protein feeding, augmented muscle fractional synthetic rate of connective tissue as early as $3-5 \mathrm{~h}$ post-exercise, suggesting that ECM remodelling is sensitive to exogenous AA and the remodelling process is rapidly modulated (Holm et al. 2017). An in vitro study also suggested stimulatory effects of $\mathrm{CP}$ on myofibrillar synthesis (Kitakaze et al. 2016); however, these effects might not translate in vivo, given the high doses used and evidence that leucine is the key anabolic trigger under these conditions (Impey et al. 2018). Thus, we believe that the $\mathrm{CP}$ had little influence on myofibrillar re-conditioning and instead any benefit was the result of cellular changes in ECM. Nonetheless, these effects are speculative at present and need to be experimentally tested.

Faster ECM remodelling would also be a plausible explanation for the improvements in CMJ performance seen with $\mathrm{CP}$ after EIMD. Indeed, the ECM plays a well-known role in force transmission during muscle contraction, so it is reasonable to assume that any dysfunction would affect force output. Although not measured in this study, a number of studies have reported damage to the ECM components following similar bouts of exercise (Mackey et al. 2004; Brown et al. 1999; Tofas et al. 2008). It is conceivable that attenuation of this damage or acceleration of the remodelling process could enable the muscles to transmit forces more efficiently throughout the fibre in turn supporting contractile force output. However, in this scenario, we would also expect MIVC to be significantly altered by the $\mathrm{CP}$ which was not the case, 
apart from a small possible benefit at $24 \mathrm{~h}$ post-exercise $(E S=0.51)$. The reason for the discrepant finding between CMJ and MIVC is not entirely clear, but it is well established that the two measures do not correlate (Clifford et al. 2016b). It is possible that the greater inter-participant variability for the MIVC vs. CMJ measure hampered our ability to detect larger group differences in the former. Regardless of the precise reasons, more detailed mechanistic studies with muscle biopsies are required in the future to elucidate the aforementioned mechanisms.

There were no statistically significant changes in serum proteins ALT, AST, LDH and CK. Possibly and likely beneficial reductions were observed in ALT, AST and CK following CP ingestion with MBI analysis; however, these effects were small to moderate. These findings are in contrast to recent study that reported significant reductions in plasma $\mathrm{CK}$ and $\mathrm{LDH}$ in the 24-72 $\mathrm{h}$ following muscle-damaging exercise with $3 \mathrm{~g}$ of CP ingestion (Lopez et al. 2015). The discrepancy in findings between our study and that of Lopez et al. (2015) could be due to the much higher inter-individual variability for these markers in our study. Indeed, the heterogenic responses could be why we were unable to detect subtle differences between group changes with traditional statistical tests and only with MBI analysis. The general pattern of these intracellular proteins being reduced with MBI analysis suggests a possible attenuation of muscle damage or a better maintenance of ultrastructural integrity with $\mathrm{CP}$ ingestion, which would be consistent with the accelerated recovery of CMJ performance. However, because the group differences were only small to moderate $(\mathrm{ES}<0.80)$ and not statistically significant $(P<0.05)$ it is unclear how meaningful these changes are.

In a recent study, Shaw et al. (2016) reported that $15 \mathrm{~g}$ of gelatin, which led to marked increases in systemic levels of glycine, hydroxyproline and proline, stimulated collagen synthesis, as measured by a significant augmentation of P1NP, a marker of bone formation. These findings were interpreted to suggest that the gelatin-induced hyperaminoacidaemia could augment post-exercise collagen synthesis when ingested $1 \mathrm{~h}$ before physical activity. These findings were intriguing and, therefore, we decided to measure P1NP in the present study, alongside the bone resorption marker $\beta$-CTX, to see if similar effects were present in our model. We also reasoned that in the absence of muscle biopsies, these findings might shed some light on the potential for $\mathrm{CP}$ to augment collagen synthesis in vivo. Nonetheless, in contrast to the findings of Shaw et al. (2016), we found that apart from a small possible increase at $1.5 \mathrm{~h}$ post-exercise $(\mathrm{ES}=0.16) \mathrm{P} 1 \mathrm{NP}$ was largely unaffected by $\mathrm{CP}$ supplementation. Similarly, apart from a small possible increase in B-CTX levels at $24 \mathrm{~h}$ post-exercise in $\mathrm{CP}$ in which the effect size was not large enough to be considered meaningful (0.09) at all other time points, CP did not influence bone resorption levels. We are unsure as to why we found such discrepant findings, but differences in supplement and dose used (10 g twice per day of CP vs. $15 \mathrm{~g}$ of gelatin), exercise model (drop jumps vs. skipping) and analytical methods (electro-chemiluminescence vs. ELISA) could provide at least a partial explanation. Regardless, our data do not support the idea that acute $\mathrm{CP}$ ingestion stimulates bone collagen synthesis after strenuous physical exercise. It is likely that a longer supplementation period is required for these effects to manifest; indeed, a recently published study found that 12 months of daily $\mathrm{CP}$ ingestion $(5 \mathrm{~g})$ increased P1NP and decreased $\beta$-CTX in post-menopausal women (König et al. 2018). Future studies should assess the effects of longer supplementation periods on bone turnover in physically active individuals.

The main limitation of this study is that due to ethical constraints, we were unable to take muscle biopsy samples in this study, instead having to rely on indirect markers of muscle damage and inflammation to evaluate the effects of CP. We do not perceive this to be a limitation in terms of assessing function and subjective wellbeing as muscle soreness and muscle function are still the most valid and reliable measures of EIMD with the most practical relevance (Warren et al. 1999). However, the changes we observed at the systemic level might not reflect the changes at the local level, and thus, we must emphasize caution when interpreting these findings. Moreover, that there is no evidence to date that $\mathrm{CP}$ influences connective tissue synthesis in vivo, we are unable to provide any concrete evidence as to the possible mechanisms involved, but hope this research stimulates further studies in this area.

In conclusion, this study showed that 9 days of $\mathrm{CP}$ supplementation might help to accelerate the recovery of muscle function and attenuate muscle soreness following strenuous physical exercise. The underlying mechanisms remain unclear, but we speculate that they are related to an increase in collagen synthesis in the connective tissues surrounding the muscle and/or modulation of the inflammatory response to the exercise bout, which could accelerate the early remodelling process. In addition to testing this hypothesis, future studies are needed to evaluate the optimal dose and whether such effects are present in elite athletic populations.

Acknowledgements This study was funded by Rousselot BVBA. The funders supplied the supplements used in this study but had no role in the analysis, interpretation of the results, and writing of the manuscript. Barbara Vanhoecke and Janne Prawitt are employees of Rousselot.

\section{Compliance with ethical standards}

Conflict of interest All the other authors declare no conflict of interest.

Ethical statement All the study procedures were in accordance with the ethical standards of the institutional research ethics committee and 
with the 1964 Helsinki Declaration and its later amendments or comparable ethical standards.

OpenAccess This article is distributed under the terms of the Creative Commons Attribution 4.0 International License (http://creativeco mmons.org/licenses/by/4.0/), which permits unrestricted use, distribution, and reproduction in any medium, provided you give appropriate credit to the original author(s) and the source, provide a link to the Creative Commons license, and indicate if changes were made.

\section{References}

Batterham AM, Hopkins WG (2006) Making meaningful inferences about magnitudes. Int J Sports Physiol Perform 1(1):50-57

Brown S, Day S, Donnelly A (1999) Indirect evidence of human skeletal muscle damage and collagen breakdown after eccentric muscle actions. J Sports Sci 17(5):397-402

Clark KL, Sebastianelli W, Flechsenhar KR, Aukermann DF, Meza F, Millard RL, Deitch JR, Sherbondy PS, Albert A (2008) 24-Week study on the use of collagen hydrolysate as a dietary supplement in athletes with activity-related joint pain. Curr Med Res Opin 24(5):1485-1496

Clarkson PM, Sayers SP (1999) Etiology of exercise-induced muscle damage. Can J Appl Physiol 24(3):234-248

Clifford T, Allerton DM, Brown MA, Harper L, Horsburgh S, Keane KM, Stevenson EJ, Howatson G (2016a) Minimal muscle damage after a marathon and no influence of beetroot juice on inflammation and recovery. Appl Physiol Nutr Metab 42(3):263-270

Clifford T, Bell O, West DJ, Howatson G, Stevenson EJ (2016b) The effects of beetroot juice supplementation on indices of muscle damage following eccentric exercise. Eur J Appl Physiol 116(2):353-362

Connolly DA, McHugh MP, Padilla-Zakour OI (2006) Efficacy of a tart cherry juice blend in preventing the symptoms of muscle damage. Br J Sports Med 40(8):679-683

Crameri RM, Aagaard P, Qvortrup K, Langberg H, Olesen J, Kjær M (2007) Myofibre damage in human skeletal muscle: effects of electrical stimulation versus voluntary contraction. J Physiol 583(1):365-380

Dannecker EA, Koltyn KF (2014) Pain during and within hours after exercise in healthy adults. Sports Med 44(7):921-942

Dar QA, Schott EM, Catheline SE, Maynard RD, Liu Z, Kamal F, Farnsworth CW, Ketz JP, Mooney RA, Hilton MJ, Jonason JH (2017) Daily oral consumption of hydrolyzed type 1 collagen is chondroprotective and anti-inflammatory in murine posttraumatic osteoarthritis. PLoS One 12(4):e0174705

Flechsenhar K, McAlindon T (2016) Change in serum biomarkers in patients with osteoarthritis treated with collagen hydrolysate: results of a prospective randomized study. J Arthritis. https://doi. org/10.4172/2167-7921.1000219

Gillies AR, Lieber RL (2011) Structure and function of the skeletal muscle extracellular matrix. Muscle Nerve 44(3):318-331

Halsey LG, Curran-Everett D, Vowler SL, Drummond GB (2015) The fickle $P$ value generates irreproducible results. Nat Methods 12(3): 179

Han XY, Wang W, Komulainen J, Koskinen SO, Kovanen V, Vihko V, Trackman PC, Takala TE (1999) Increased mRNAs for procollagens and key regulating enzymes in rat skeletal muscle following downhill running. Pflügers Arch 437(6):857-864

Holm L, Rahbek SK, Farup J, Vendelbo MH, Vissing K (2017) Contraction mode and whey protein intake affect the synthesis rate of intramuscular connective tissue. Muscle Nerve 1:128-130
Hopkins WG (2002) A scale of magnitude for effect statistics. A new view of statistics. Victoria University, Melbourne, p 502. http:// www.sportsci.org/resource/stats/

Hyldahl RD, Hubal MJ (2014) Lengthening our perspective: morphological, cellular, and molecular responses to eccentric exercise. Muscle Nerve 49(2):155-170

Impey SG, Hammond KM, Naughton R, Langan-Evans C, Shepherd SO, Sharples AP, Cegielski J, Smith K, Jeromson S, Hamilton DL, Close GL (2018) Whey protein augments leucinemia and post-exercise p70S6K1 activity compared to a hydrolysed collagen blend when in recovery from training with low carbohydrate availability. Int J Sport Nutr Exerc Metab. https://doi. org/10.1123/ijsnem.2018-0054

Kitakaze T, Sakamoto T, Kitano T, Inoue N, Sugihara F, Harada N, Yamaji R (2016) The collagen derived dipeptide hydroxyprolylglycine promotes $\mathrm{C} 2 \mathrm{C} 12$ myoblast differentiation and myotube hypertrophy. Biochem Biophys Res Commun 478(3):1292-1297

König D, Oesser S, Scharla S, Zdzieblik D, Gollhofer A (2018) Specific collagen peptides improve bone mineral density and bone markers in postmenopausal women-a randomized controlled study. Nutrients 10(1):97

Kumar S, Sugihara F, Suzuki K, Inoue N, Venkateswarathirukumara S (2015) A double-blind, placebo-controlled, randomised, clinical study on the effectiveness of collagen peptide on osteoarthritis. J Sci Food Agric 95(4):702-707

Lau WY, Muthalib M, Nosaka K (2013) Visual analog scale and pressure pain threshold for delayed onset muscle soreness assessment. J Musculoskelet Pain 21(4):320-326

Li P, Wu G (2018) Roles of dietary glycine, proline, and hydroxyproline in collagen synthesis and animal growth. Amino Acids 50(1):29-38

Lopez HL, Ziegenfuss TN, Park J (2015) Evaluation of the effects of biocell collagen, a novel cartilage extract, on connective tissue support and functional recovery from exercise. Integr Med Clin J 14(3):30

Mackey AL, Kjaer M (2016) Connective tissue regeneration in skeletal muscle after eccentric contraction-induced injury. J Appl Physiol 122(3):533-540

Mackey AL, Donnelly AE, Turpeenniemi-Hujanen T, Roper HP (2004) Skeletal muscle collagen content in humans after highforce eccentric contractions. J Appl Physiol 97(1):197-203

Miller BF, Olesen JL, Hansen M, Døssing S, Crameri RM, Welling RJ, Langberg H, Flyvbjerg A, Kjaer M, Babraj JA, Smith K (2005) Coordinated collagen and muscle protein synthesis in human patella tendon and quadriceps muscle after exercise. J Physiol 567(3):1021-1033

Mizumura K, Taguchi T (2016) Delayed onset muscle soreness: involvement of neurotrophic factors. J Physiol Sci 66(1):43-52

Ohara H, Matsumoto H, Ito K, Iwai K, Sato K (2007) Comparison of quantity and structures of hydroxyproline-containing peptides in human blood after oral ingestion of gelatin hydrolysates from different sources. J Agric Food Chem 55(4):1532

Page P (2014) Beyond statistical significance: clinical interpretation of rehabilitation research literature. Int J Sports Phys Ther 9(5):726

Paulsen G, Ramer Mikkelsen U, Raastad T, Peake JM (2012) Leucocytes, cytokines and satellite cells: what role do they play in muscle damage and regeneration following eccentric exercise? Exerc Immunol Rev 1:18

Shaw G, Lee-Barthel A, Ross ML, Wang B, Baar K (2016) Vitamin C-enriched gelatin supplementation before intermittent activity augments collagen synthesis. Am J Clin Nutr 105(1):136-143

Shearer DA, Sparkes W, Northeast J, Cunningham DJ, Cook CJ, Kilduff LP (2017) Measuring recovery: an adapted Brief Assessment of Mood (BAM +) compared to biochemical and power output alterations. J Sci Med Sport 20(5):512-517 
Sousa M, Teixeira VH, Soares J (2013) Dietary strategies to recover from exercise-induced muscle damage. Int J Food Sci Nutr 65(2):151-163

Stauber WT, Clarkson PM, Fritz VK, Evans WJ (1990) Extracellular matrix disruption and pain after eccentric muscle action. J Appl Physiol 69(3):868-874

Tofas T, Jamurtas AZ, Fatouros I, Nikolaidis MG, Koutedakis Y, Sinouris EA, Papageorgakopoulou N, Theocharis DA (2008) Plyometric exercise increases serum indices of muscle damage and collagen breakdown. J Strength Cond Res 22(2):490-4966

Townsend R, Elliott-Sale KJ, Currell K, Tang J, Fraser WD, Sale C (2017) The effect of postexercise carbohydrate and protein ingestion on bone metabolism. Transl J Am Coll Sports Med 2(20):129-137

Warren GL, Lowe DA, Armstrong RB (1999) Measurement tools used in the study of eccentric contraction-induced injury. Sports Med 27(1):43-59

Woo T, Lau L, Cheng N, Chan P, Tan K (2017) Efficacy of oral collagen in joint pain-osteoarthritis and rheumatoid arthritis. J Arthritis 6(233):2
Zdzieblik D, Oesser S, Gollhofer A, König D (2017) Improvement of activity-related knee joint discomfort following supplementation of specific collagen peptides. Appl Physiol Nutr Metab 42(6):588-595

Zou Y, Zwolanek D, Izu Y, Gandhy S, Schreiber G, Brockmann K, Devoto M, Tian Z, Hu Y, Veit G, Meier M (2014) Recessive and dominant mutations in COL12A1 cause a novel EDS/myopathy overlap syndrome in humans and mice. Hum Mol Genet 23(9):2339-2352

Publisher's Note Springer Nature remains neutral with regard to jurisdictional claims in published maps and institutional affiliations. 